\title{
Expression and prognostic analyses of early growth response proteins (EGRs) in human breast carcinoma based on database analysis
}

\author{
Yuchang Fei ${ }^{1}$, Huan Yu ${ }^{2}$, Shuo Huang ${ }^{1}$, Peifeng Chen ${ }^{3}$, Lei Pan ${ }^{\text {Corresp. } 3}$ \\ ${ }^{1}$ First Clinical Medical Institute of Zhejiang Chinese Medical University, Hangzhou, Zhejiang Province, China \\ 2 Ningbo Yinzhou Second Hospital, Ningbo, Zhejiang Province, China \\ 3 Medical Oncology, The First Affiliated Hospital of Zhejiang Chinese Medical university, Hangzhou, Zhejiang Province, China \\ Corresponding Author: Lei Pan \\ Email address: panlei21316@163.com
}

Background. Early growth response proteins (EGRs), as a transcriptional regulatory family, are involved in the process of cell growth, differentiation, apoptosis, and even carcinogenesis. However, the role of EGRs in tumors, their expression levels, and their prognostic value remain unclear.

Methods. Using the Oncomine database, Kaplan-Meier Plotter, bcGenExMiner v4.2, cBioPortal , and other tools, the association between the survival data of breast carcinoma (BC) patients and transcriptional levels of four EGRs was investigated.

Results. According to the Oncomine database, in comparison to normal tissues, the expression level of EGR2/3 mRNA in BC tissues was decreased, but there was no difference in the expression level of EGR4 mRNA. On the basis of the Scarff-Bloom-Richardson (SBR) grading system, the downregulated expression

level of EGR1/2/3 and upregulated expression level of EGR4 were correlated with an increased histological differentiation level, with significant differences $(p<0.05)$. Kaplan-Meier curves suggest that a reduction in EGR2/3 mRNA expression is related to recurrence-free survival (RFS) in BC patients. In addition, the mRNA expression level of EGR1/2/3 was related to metastatic relapse-free survival (MRFS) in $B C$ patients with metastatic recurrence $(p<0.05)$.

Conclusion. EGR1/2/3 can be utilized as an important factor for evaluating prognosis and may be relevant to diagnosis. EGR4 may play a role in the occurrence and development of $B C$. The specific function and mechanism of EGRs in BC deserve further study. 
1 Expression and prognostic analyses of early growth

2 response proteins (EGRs) in human breast carcinoma

3 based on database analysis

4

5

6

7

Yuchang Fei ${ }^{1}$, Huan $\mathrm{Yu}^{2}$, Shuo Huang ${ }^{1}$, Peifeng $\mathrm{Chen}^{3}$,Lei $\mathrm{Pan}^{3}$

${ }^{1}$ First Clinical Medical Institute of Zhejiang Chinese Medical University, Zhejiang, P.R. China

2 Ningbo Yinzhou Second Hospital, Ningbo, Zhejiang, P.R. China

${ }^{3}$ Medical Oncology, The First Affiliated Hospital of Zhejiang Chinese Medical university, Hangzhou, Zhejiang, P.R. China

Corresponding Author:

Lei $\operatorname{Pan}^{3}$

No.54 Youdian Road, Shangcheng District, Zhejiang Provincial Hospital of TCM, Hangzhou, Zhejiang ,310006, P.R. China

Email address: panlei21316@163.com

\section{Abstract}

Background. Early growth response proteins (EGRs), as a transcriptional regulatory family, are involved in the process of cell growth, differentiation, apoptosis, and even carcinogenesis. However, the role of EGRs in tumors, their expression levels, and their prognostic value remain unclear.

Methods. Using the Oncomine database, Kaplan-Meier Plotter, bcGenExMiner v4.2, cBioPortal, and other tools, the association between the survival data of breast carcinoma (BC) patients and transcriptional levels of four EGRs was investigated.

Results. According to the Oncomine database, in comparison to normal tissues, the expression level of EGR2/3 mRNA in BC tissues was decreased, but there was no difference in the expression level of EGR4 mRNA. On the basis of the Scarff-Bloom-Richardson (SBR) grading system, the downregulated expression level of EGR1/2/3 and upregulated expression level of EGR4 were correlated with an increased histological differentiation level, with significant differences $(p<0.05)$. Kaplan-Meier curves suggest that a reduction in EGR2/3 mRNA expression is related to recurrence-free survival (RFS) in BC patients. In addition, the mRNA expression level of EGR1/2/3 was related to metastatic relapse-free survival (MRFS) in BC patients with metastatic recurrence $(p<0.05)$.

Conclusion. EGR1/2/3 can be utilized as an important factor for evaluating prognosis and may be relevant to diagnosis. EGR4 may play a role in the occurrence and development of BC. The 
specific function and mechanism of EGRs in BC deserve further study.

Key words: Early growth response proteins, breast carcinoma, prognosis, bioinformatic analyses.

\section{Introduction}

Breast carcinoma (BC) is currently the major cause of cancer-related deaths in women worldwide. According to 2012 data, there are approximately 1.7 million new cases and over half a million deaths each year. $\mathrm{BC}$ alone accounts for $25 \%$ of all cancer cases and $15 \%$ of cancer deaths in women. Worldwide, the incidence and mortality related to BC ranks first among female cancers (Torre L A et al., 2015). In many Asian and African countries, morbidity and mortality have been increasing compared to those in Europe and the United States. This finding may be ascribed to westernized lifestyle changes and a lack of $\mathrm{BC}$ screening activities (Desantis $\mathrm{C}$ et al., 2014). BC has a variety of clinical, pathological, and molecular characteristics. The detection of the biological markers of $\mathrm{BC}$, such as progesterone receptor (PR), estrogen receptor (ER), and tyrosine kinase ErbB2 receptor (HER2), can better predict the treatment and prognosis of patients (Onitilo AA et al., 2009).

Early growth response proteins (EGRs) are a transcriptional regulatory family and include EGR1/2/3/4. These proteins possess the ability to bind GC-rich recognition motifs in DNA (Gashler A, 1995) and mediate the processes involved in cell growth, differentiation, and apoptosis. As an anticancer gene, EGR1 has been observed and verified in numerous cancers. It has also been completely absent in breast cancer and lung cancer (Huang RP et al., 1995; Ronski $\mathrm{K}$ et al., 2010). EGR1 plays a biological role in tumor cells by regulating the transcription of the heparin enzyme and either an inhibitory or an activation role in different tumor types (De Mestre A M et al., 2005). Chen et al. (Chen D G et al., 2017) successfully inhibited the proliferation of glioma by knocking out EGR1. EGR1 is highly expressed in prostate cancer and is deemed to be the key factor that drives tumor progression (Ma J et al., 2009). In ER+ breast tumors that were treated with endocrine therapy, the higher the expression level of EGR1 was, the better the prognosis (Shajahanhaq A N et al., 2017). In addition, EGR2 has been discovered to inhibit the growth and invasion of SGC-7901 cells in gastric cancer, which implies that it may have an anticancer effect (Chen P et al., 2016). Specifically, the researchers (Chen M et al., 2019) inhibited gastric cancer metastasis and the epithelial-mesenchymal process by upregulating the expression of EGR2. EGR3 has been recognized to play a vital role in the invasion of $\mathrm{BC}$ and is an independent prognostic factor for BC (Suzuki T et al., 2007). The upregulation of EGR3 improves the survival and proliferation ability of hepatocellular carcinoma (HCC) cells and promotes the migration and invasion of HCC cells (Baron V T et al., 2015). Su et al. (He S et al., 2019) confirmed that the upregulation of EGR4 may promote the growth of non-small cell lung cancer (NSCLC) through the positive feedback regulatory circuit formed between ZNF205-AS1 and EGR4. Based on previous studies, EGR2, EGR3, and EGR4 were described as key regulators of T-cell activation in vivo and in vitro (Williams JB et al., 2017). Their potential role in cancer has been receiving increasing attention. 
With the development of genomics, the genetic map of BC has continued to gain improvement. However, the identification of effective gene therapy targets for $\mathrm{BC}$ has become an urgent matter. This study examined the expression of the EGR gene family in tumor databases. Additionally, their expression in $\mathrm{BC}$ was analyzed to elucidate its value in the treatment and diagnosis of BC.

\section{Materials \& Methods}

\section{Oncomine Database Analysis}

Oncomine (https://www.oncomine.org) is a large tumor gene microarray database covering 65 gene chip datasets, 4,700 chips and 480 million gene expression data points that can be used to analyze gene expression differences (Rhodes DR et al., 2004). The specific retrieval parameters used were as follows: Retrieve: EGR1/2/3/4; Data type: mRNA; Analysis type: cancer and normal analysis; P value: 0.0001; Fold change: 2.0; Gene rank: 10\%; Analysis execution time: 2019.06.29. These data were collected from significantly different studies.

\section{The Cancer Genome Atlas (TCGA) and the Molecular Taxonomy of Breast Cancer International Consortium (METABRIC)}

The Cancer Genome Atlas (TCGA) (https://portal.gdc.cancer.gov/) is a cancer gene database that enables genome sequencing and bioinformatics analyses through high-throughput genome analysis technology and includes 39 different cancer types. The Molecular Taxonomy of Breast Cancer International Consortium (METABRIC) (http://molonc.bccrc.ca/apariciolab/research/metabric/) is a project established by Canada and the UK that aims to classify BC according to its molecular characteristics to obtain the best clinical treatment. We used cBioPortal to visualize the data from the TCGA and METABRIC databases.

\section{cBioPortal}

cBioPortal (https://www.cbioportal) is a visualized analysis tool set that contains the genetic expression data and pathological information of 3617 BC patients. It further analyzes the expression of EGR family members through the exploration of multidimensional cancer gene set data. The retrieval parameters used were as follows: Analysis of cancer: breast cancer; Data set: Breast Cancer (METABRIC, Nature 2012 \& Nat Commun 2016), Breast Invasive Carcinoma (TCGA, Provisional); Select Genomic Profiles: Mutations and copy-number alterations; Enter Genes: EGR1, EGR2, EGR3, EGR4.

\section{Kaplan-Meier Plotter}

The Kaplan-Meier curves were generated by Kaplan-Meier Plotter (URL:

https://www.kmplot.com) to analyze the prognostic value of EGR expression in BC (Nagy A et al., 2018). The site contains the clinical information of 6234 patients with BC. Each gene was divided into two groups: a high expression group and a low expression group, which were classified in accordance with median mRNA expression values. The required probe ids were then encoded into the database. Kaplan-Meier curves were subsequently plotted, and the overall survival (OS), recurrence-free survival (RFS), distant metastasis-free survival (DMFS), and post progression survival (PPS) of different genes in various BC subtypes were evaluated. 
116 Breast Cancer Gene-Expression Miner v4.2 (bcGenExMiner v4.2)

117 The Breast Cancer Gene-Expression Miner (bcGenExMiner) tool v4.2

118 (http://bcgenex.centregauducheau.fr/bc-gem/GEM-Accueil.php?js=1) is a statistical mining tool

119 with published annotated transcriptome BC data (DNA microarray and RNA-seq data), which

120 comprises 36 genomic data sets that are annotated (updated to January 2019) to analyze the

121 relationship between EGR family mRNA expression levels and clinical parameters (age, ER, PR, 122 HER2, etc.) (Jézéquel P et al., 2012; Jézéquel P et al., 2013).

123

124

125

126

127

128

129

130

131

132

133

134

135

136

137

138

139

140

141

142

143

144

145

146

147

148

149

150

151

152

153

154

155

\section{Statistical Analysis}

Using Student's t-test (Hsu C L, Lee W C, 2010) on the Oncomine data set for analysis, we established that differences with $\mathrm{p}<0.0001$ or 2.0 -fold changes were statistically significant. BcGenExMiner v4.2 was used to conduct Tukey-Kramer's test, the Welch test and univariate Cox analysis.

\section{Results}

The EGR mRNA expression levels in BC tissues. The mRNA expression levels of EGR family members in BC samples were compared with those in normal tissues (Fig. 1). The analysis showed that EGR1 and EGR2 were significantly downregulated in patients with BC in 17 $(35.4 \%)$ and $14(53.8 \%)$ datasets, respectively, and EGR3 was also significantly downregulated in four datasets. However, no relevant dataset indicated a difference in the expression level of EGR4. In the TCGA dataset, which contains 593 genetic samples from patients with BC, EGR1 expression was discovered in different invasive BCs and was significantly lower in BC (invasive ductal breast cancer: fold change -14.944; invasive lobular breast cancer: fold change -7.001; invasive breast cancer: fold change -6.692) (Table 1). According to the study by Curtis et al. (Curtis C et al., 2012), EGR1 was significantly downregulated in different pathological types of BC. In the TCGA dataset, EGR2 exhibited a fold change of -3.173 in invasive BC, while EGR3 showed a fold change of -4.301 in invasive BC.

\section{The EGR mRNA expression levels of patients with BC are significantly correlated with} clinicopathological data. We used bcGenExMiner v4.2 to analyze the mRNA expression of the EGR family and various clinicopathological parameters and classified the data, as illustrated in Table 2. In ER-positive BC patients, EGR1/3 expression levels were significantly upregulated $(p<0.0001)$, while EGR2/4 expression levels were significantly downregulated (EGR2: $p$ $=0.0104$, EGR4: $\mathrm{p}<0.0001)$. In PR-positive BC patients, EGR1/3 expression levels were significantly upregulated $(\mathrm{p}<0.0001)$, and EGR4 was significantly downregulated (EGR4: $\mathrm{p}=0.0009$ ). Among BC patients with positive HER2, only EGR1 was significantly downregulated $(\mathrm{p}=0.0297)$. When the nodule status was positive, EGR1/4 expression levels were significantly downregulated (EGR1: $\mathrm{p}=0.0338$, EGR4: $\mathrm{p}=0.0016$ ). However, when BC patients were over 51 years of age, there were no statistically significant differences in EGR1 mRNA expression, and EGR2/3/4 expression levels were significantly downregulated (EGR2: $\mathrm{p}=0.0387$, EGR3: $p=0.002$; EGR4, $p=0.0285$ ). The expression level of EGR1/4 in the triple-negative breast cancer $(\mathrm{TNBC})$ group decreased $(\mathrm{p}<0.0001)$. 
156 The different biological subtypes of BC and the influence of EGR expression levels on prognosis.

157 Currently, the breast oncology field mainly classifies BC into four fixed biological subtypes:

158 luminal A (ER+/HER2-/grade 1 or grade 2), luminal B (ER+/HER2-/grade 3), HER2 rich (any

159 HER2+ tumor), and basal-like (ER-/PR-/HER2-). The treatment regimens and prognosis of the

160 various biological subtypes are different (Cejalvo J M et al., 2017). Therefore, we analyzed the

161 prognosis of the four underlying subtypes in relation to EGR expression using Kaplan-Meier

162 Plotter. Analysis revealed that EGR1 was correlated with the four biological subtypes regarding

163 RFS (Fig. 2-a, b, c, d). The reduction in EGR1 was correlated with high OS and high RFS in the

164 basal-like group (Fig. 2-e, f) and was also related to high DMFS in patients who belonged to the

165 HER2+ group. However, the high expression of EGR2 showed better RFS and DMFS rates in

166 the luminal B group (Fig. 2-g, h). In contrast, the low expression of EGR2 exhibited better PPS

167 in the luminal B group (Fig. 2-i). Highly expressed EGR3 showed good RFS in the basal-like

168 group and the luminal B group. The abovementioned results are summarized in Fig. 2.

169 According to the SBR classification criteria, the relationship between EGR expression level and

$170 B C$ progression was evaluated. The histological grading of breast cancer is closely related to

171

172

173

174

175

176

177 prognosis. The Scarff-Bloom-Richardson (SBR) grading system, the most commonly used histological grading system at present, evaluates prognosis and guides chemotherapy by describing the differentiation degree of breast tumors (Amat S et al., 2002; Cherry Bansal et al., 2012). The classification was determined according to three histological features of breast tumors: the glands and composition, the proportion of the nucleus of the gland pleomorphic, and the activity of nuclear fission. The overall rating of the final score together with the above three items were divided into three levels (I-III): grades $3 \sim 5$ were classified as level I , grades $6 \sim 7$

were classified as level II and grades $8 \sim 9$ were classified as level III. We used the bcGenExMiner v4.2 analysis tool to analyze the relation between the EGR expression levels and SBR grading of BC patients. Fig. 3 illustrates the box plot results. According to the analysis results, all EGR expression levels are correlated with SBR classification. The decreased expression of EGR1, EGR2, and EGR3 indicated the progress of SBR grading. Additionally, the differences were statistically significant (Fig.3-a, b, c: EGR1/3, p<0.0001; EGR2, p=0.0007). The increased expression of EGR4 suggested the progression of SBR grading (Fig.3-d: EGR4, $\mathrm{p}<0.0001)$. The statistical results of the EGRs and SBR grading in each group were obtained using the Dunnett-Tukey-Kramer's test (Table 3). There was no significant difference between EGR2/4 expression and SBR classification.

The association of EGR expression levels with survival. EGR1/2/3 mRNA expression levels were related to MRFS in BC patients with metastatic recurrence (Fig. 4). The prognostic analysis in bcGenExMiner v4.2 showed a correlation between EGR1/2/3 mRNA expression levels and metastatic MRFS in BC patients. Patients with increased EGR 1/2/3 expression showed decreased MRFS (EGR1: HR 0.87; 95\% CI 0.77-0.98, $\mathrm{p}=0.0212$; EGR2: HR, 0.81; 95\% CI 0.71-0.92, $\mathrm{p}=0.0009$; EGR3: HR 0.78, 95\% CI 0.69-0.89, $\mathrm{p}=0.0001$; Fig. 4-a, b, c). There was no correlation between the expression of EGR4 (HR 1.09; 95\% CI 0.96-1.24, $\mathrm{p}=0.1660$ ) and MRFS 
in BC patients (Fig. 4-d).

$E G R$ mutations in $B C$. We used the cBioPortal database for gene expression analysis and EGR family prognostic assessment. Among the 3617 data samples, 165 (5\%, data not shown) samples showed changes in EGR expression levels $(0.6 \%$ of the samples showed changes in EGR1 expression, $1.4 \%$ of the samples showed changes in EGR 2 expression, $2.9 \%$ of the samples showed changes in EGR3 expression, and $0.6 \%$ of the samples showed changes in EGR4 expression) (Fig. 5-a). In invasive BC patients, the expression of EGR1/2 was upregulated, while EGR3 expression was absent. Changes in EGR4 expression were nonsignificant. There was no obvious correlation with OS ( $p=0.813$, Fig. 5-b). Moreover, there was no significant correlation between the number of copies of EGR3 and its mRNA expression level (Fig. 5-c).

\section{Discussion}

EGRs belong to the early response group gene, which is a zinc finger transcription factor that can bind to GC-rich sequences in a limited manner (Thiel G, Cibelli G, 2002). EGRs possess a variety of biological functions. By regulating genes, EGRs enable cells to go through different stages of their life cycles and participate in cell proliferation, differentiation, apoptosis, and carcinogenesis according to specific cell types and under stimulation conditions (Oliveira Fernandes M, Tourtellotte W G, 2015). EGR1 was first discovered in the screening of gene recognition upregulated by the addition of serum. The EGR2/3/4 genes were immediately discovered one year later (Santino P et al., 2017). However, there have been no detailed reports on the association between the EGR family and the occurrence, development, and prognosis of BC. Therefore, this study carried out further evaluation and analysis.

EGR1 (one of the components of the early growth response family) can be activated instantaneously after being induced by various external stimuli (Silverman E S, Collins T., 1999). As upstream and downstream molecules of various signaling pathways, EGR1 can regulate the expression of target genes. Shen et al. discovered that EGR1 can be stimulated and induced by various cytokines and hormones through the MAPK/ERK1/2 signaling pathway, thereby regulating the expression of target genes, which cause cell differentiation, apoptosis, and other pathophysiological processes (Delmastro M M, Piganelli J D, 2011). Currently, the signaling pathway mediated by EGR1 is known to be of great significance in terms of the development of female reproductive organs (Russell D L et al., 2003). However, its specific role in BC is still unclear. In this study, the mRNA expression of EGR1 in BC samples was lower than that in normal breast tissues. Moreover, EGR1 expression was not consistent under different pathological characteristics: EGR1 was upregulated in $\mathrm{ER}(+)$ or $\mathrm{PR}(+)$ patients, while it was downregulated in HER2(-) patients. Further analysis on the classification of biological subtypes showed that EGR1 was correlated with the RFS of the four biological subtypes. The decrease in EGR1 expression indicates the progression of SBR classification; moreover, BC patients with higher EGR1 expression levels exhibited better OS and RFS. The above results provide some evidence for the follow-up treatment of BC patients.

The role of EGR2 in the central/peripheral nervous system has been widely reported (LeBlanc, S. 
235

236

E, 2005; Nonchev $\mathrm{S}$ et al., 1996). In addition, EGR2 can negatively regulate the activation of Tcells and B-cells as well as the production of proinflammatory cytokines by inducing and inhibiting the expression of some cytokine signaling molecules (Li S et al., 2013). Earlier reports have verified the involvement of EGR2 in the occurrence, invasion, and migration of a wide variety of tumors. Chen et al. found that the regulation of EGR2 expression by the competitive combination of LINC01939 with mir-17-5p may inhibit the metastasis and EMT of gastric cancer(Chen M et al., 2019). EGR2 can reduce the phosphorylation of JAK2 and STAT3 by regulating the expression of SOCS-1 (Lu L et al., 2017). In addition, a lack of EGR2 results in defective cloning amplification of T-cells as a response to viral infection, with overactivation and overdifferentiation (Miao T et al., 2017). The regulatory effect of EGR2 on T-cells is crucial for maintaining immune homeostasis. Additionally, the regulation of EGR2 expression can control the immune regulatory pathway and avoid the occurrence of tumor immune escape. In the current study, it was discovered that EGR2 expression was significantly decreased in BC patients (including patients with recurrence and metastasis), and a low EGR2 expression level resulted in poor MRFS. This study found that the mRNA expression level of EGR2 in the samples of BC patients was lower than that in normal breast tissues. In addition, the upregulation of EGR2 mRNA expression in BC patients resulted in better OS and RFS, which provides a basis for EGR2 to become a biological marker for evaluating the prognosis of $\mathrm{BC}$ patients.

EGR3 has been reported in various cancers. As a direct target of mir-71, EGR3 is negatively regulated and downregulated to promote the migration and invasion of HCC cells (Wang Z D et al., 2017). Other studies have discovered that the expression level of EGR3 mRNA in prostate cancer samples is high, which can be used as a marker for cancer diagnosis and as a prognostic indicator that distinguishes between invasive and noninvasive tumors (Rebecca P et al., 2013). EGR3 activates related inflammatory signaling pathways (such as the NF-kb pathway) by activating the expression of IL-6 and IL-8, which are closely related to the occurrence and development of cancer (Baron V T et al., 2014). EGR3 has been shown to play an important role in the invasion of BC (Suzuki T et al., 2007). According to the analysis of this study, the expression of EGR3 mRNA was downregulated in BC and even absent in BC patients with metastasis and recurrence. Moreover, EGR3 was correlated with RFS in BC patients. We also found that the higher the SBR grade is, the lower the expression level of EGR3 mRNA. In addition, EGR3 mRNA expression was significantly correlated with BC MRFS. Moreover, it was an independent prognostic factor for BC. Therefore, EGR3 can be utilized as a biological marker for $\mathrm{BC}$ diagnosis and is an important indicator for prognosis.

There are few reports on EGR4 in tumors. At present, some literature suggests that EGR4 may be an oncogene that promotes the development of NSCLC (He S et al., 2019; Matsuo T et al., 2014). However, the relationship between EGR4 and the occurrence, development, and prognosis of $\mathrm{BC}$ has not been reported. In this study, the upregulated mRNA expression level of EGR4 was correlated with SBR grading but not significantly correlated with OS and RFS in BC patients. Therefore, EGR4 may be a potential oncogene in BC.

This analysis helped further our understanding of the expression level and prognostic value of the EGR family in BC and provided some evidence for the family members as new prognostic 
276 biomarkers or promising therapeutic targets for BC. However, we have focused on only the

277 mRNA expression level and prognostic value of this family, without further analysis of its

278 protein expression level and some related signaling pathways. Additional studies will explore the

279 potential molecular mechanism of EGR in BC.

280 The limitations of this study should be noted. First, screening for biomarkers was based on

281 statistical methods rather than biological experiments. Second, further conclusions need to be

282 carried out in vitro and further validated in prospective studies and multicenter clinical trials.

283 Third, due to the different emphases of different databases and different included studies, this

284 study cannot guarantee the comprehensive application of data from different data sources and

285 different databases, so the sensitivity and specificity of the data analysis results will also be

286 different.

287 Generally, the EGRs might be involved in the occurrence and development of BC. At present,

288 there are very few studies on the EGR family in BC, and they are not systematic. No expression

289 differences of the EGR family members in BC in the literature were discussed, and the specific

290 mechanism is unclear.

291

292

293

294

295

296

297

298

299

300

301

302

303

\section{4}

\section{Conclusions}

This study specifically studied the expression of EGRs in BC and evaluated its clinical and prognostic value. The data analysis results suggest that EGR2/3 may be a potential diagnostic marker for BC, which can provide a basis for the prognostic assessment of BC. EGR4 may play a role in the occurrence and development of BC. Nevertheless, our research still has shortcomings. Currently, it is limited to database mining, and further in vitro experiments will be conducted based on the above conclusions in the future.

\section{Acknowledgments}

We appreciate Oncomine (our data contributor), Kaplan-Meier Plotter, and bcGenExMiner v4.2, cBioPortal.

\section{References}

Torre LA, Bray F, Siegel RL, Ferlay J, Lortet-Tieulent J, Jemal A. 2015. Global cancer statistics. CA: A Cancer Journal for Clinicians, 65(2):87-108. DOI: 10.3322/caac.21262.

DeSantis C1, Ma J, Bryan L, Jemal A. 2014. Breast cancer statistics, 2013. CA: A Cancer Journal for Clinicians, 64(1):52-62. DOI: 10.3322/caac.21203.

Onitilo AA, Engel JM, Greenlee RT, Mukesh BN. 2009. Breast Cancer Subtypes Based on ER/PR and Her2 Expression: Comparison of Clinicopathologic Features and Survival. Clinical Medicine \& Research, 7(1-2):413. DOI: $10.3121 / \mathrm{cmr} .2009 .825$.

Gashler A, Sukhatme VP. 1995. Early growth response protein 1(Egr-1): prototype of z zinc-finger family of transcription factors. Prog.Nucleic Acid Res.Mol.Biol, 50. DOI:10.1016/S0079-6603(08)60815-6. 
314 Huang RP, Liu C, Fan Y, Mercola D, Adamson ED. 1995. Egr-1 Negatively Regulates Human Tumor Cell

315 Growth via the DNA-binding Domain. Cancer Research, 55(21):5054-5062. DOI: 10.1007/BF01517220.

316 Ronski K, Sanders M, Burleson JA, Moyo V, Benn P, Fang M. 2010. Early growth response gene 1 (EGR1)

317 is deleted in estrogen receptor-negative human breast carcinoma. Cancer, 104(5):925-930. DOI:

318 10.1002/cncr.21262.

319 de Mestre AM, Rao S, Hornby JR, Soe-Htwe T, Khachigian LM, Hulett MD. 2005. Early Growth Response 320 Gene 1 (EGR1) Regulates Heparanase Gene Transcription in Tumor Cells. Journal of Biological Chemistry, 321 280(42):35136-35147. DOI: 10.1074/jbc.m503414200.

322 Chen DG, Zhu B, Lv SQ, Zhu H, Tang J, Huang C, Li Q, Zhou P, Wang DL, Li GH. 2017. Inhibition of 323 EGR1 inhibits glioma proliferation by targeting CCND1 promoter. Journal of Experimental \& Clinical Cancer 324 Research, 36(1):186. DOI: 10.1186/s13046-017-0656-4.

325 Ma J, Ren Z, Ma Y, Xu L, Zhao Y, Zheng C, Fang Y, Xue T, Sun B, Xiao W. 2009. Targeted knockdown 326 of EGR-1 inhibits IL-8 production and IL-8 mediated invasion of prostate cancer cells through suppressing EGR327 1/NF-kappaB synergy. Journal of Biological Chemistry. DOI: 10.1074/jbc.M109.016246.

328 Shajahan-Haq AN, Boca SM, Jin L, Bhuvaneshwar K, Gusev Y, Cheema AK, Demas DD, Raghavan KS, 329 Michalek R, Madhavan S, Clarke R. 2017. EGR1 regulates cellular metabolism and survival in endocrine 330 resistant breast cancer. Oncotarget, 8(57):96865-96884. DOI: 10.18632/oncotarget.18292.

331 Chen P, Zhao H, Huang J, Yan X, Zhang Y, Gao Y. 2016. MicroRNA-17-5p promotes gastric cancer 332 proliferation, migration and invasion by directly targeting early growth response 2 . Am J Cancer Res, 6(9):20103332020.

334 Chen M, Fan L, Zhang SM, Li Y, Chen P, Peng X, Liu DB, Ma C, Zhang WJ, Zou ZW, Li PD. 2019. 335 LINC01939 inhibits the metastasis of gastric cancer by acting as a molecular sponge of mi R-17-5p to regulate 336 EGR2 expression. Cell Death Dis, 10(2):70. DOI : 10.1038/s41419-019-1344-4.

337 Suzuki T, Inoue A, Miki Y, Moriya T, Akahira J, Ishida T, Hirakawa H, Yamaguchi Y, Hayashi S, Sasano 338 H. 2007. Early growth responsive gene 3 in human breast carcinoma: a regulator of estrogen-meditated invasion 339 and a potent prognostic factor. Endocrine Related Cancer, 14(2):279-292. DOI: 10.1677/ERC-06-0005.

340 Baron VT, Pio R, Jia Z, Mercola D. 2015. Early Growth Response 3 regulates genes of inflammation and 341 directly activates IL6 and IL8 expression in prostate cancer. British Journal of Cancer, 112(4):755-764. DOI: $34210.1038 /$ bjc.2014.622.

343 He S, Lin J, Xu Y, Lin L, Feng J. 2019. A positive feedback loop between ZNF205-AS1 and EGR4 promotes non-small cell lung cancer growth. J Cell Mol Med, 23(2):1495-1508. DOI: 10.1111/jcmm.14056.

Williams JB, Horton BL, Zheng Y, Duan Y, Powell JD, Gajewski TF. 2017. The EGR2 targets LAG-3 and 4-1BB describe and regulate dysfunctional antigen-specific CD8+ T cells in the tumor microenvironment. Journal of Experimental Medicine, 214(2):381. DOI: 10.1084/jem.20160485.

348 Rhodes DR, Yu J, Shanker K, Deshpande N, Varambally R, Ghosh D, Barrette T, Pandey A, Chinnaiyan 349 AM. 2004. Oncomine: a cancer microarray database and integrated data-mining platform. Neoplasia,6:1-6. DOI: 350 10.1016/S1476-5586(04)80047-2.

351 Nagy Á, Lánczky A, Menyhárt O, Győrffy B. 2018. Validation of miRNA prognostic power in hepatocellular 352 carcinoma using expression data of independent datasets. Scientific Reports,2018, 8(1):9227-. DOI: 353 10.1038/s41598-018-27521-y.

354 Matsuo T, Dat le T, Komatsu M, Yoshimaru T, Daizumoto K, Sone S, Nishioka Y, Katagiri T. 2014. Early 
growth response 4 is involved in cell proliferation of small cell lung cancer through transcriptional activation of its downstream genes. PLoS One, 9(11):e113606. DOI: 10.1371/journal.pone.0113606.

Tourtellotte WG, Nagarajan R, Bartke A, Milbrandt J. et al. 2000. Functional compensation by Egr4 in Egr1 dependent luteinizing hormone regulation and Leydig cell steroidogenesis. Mol Cell Biol, 20: 5261-5268. DOI: 10.1128/MCB.20.14.5261-5268.2000.

Jézéquel P, Campone M, Gouraud W, Guérin-Charbonnel C, Leux C, Ricolleau G, Campion L. 2012. BcGenExMiner: An easy-to-use online platform for gene prognostic analyses in breast cancer. Breast Cancer Res Treat,131: 765-775, 2012. 14. DOI: 10.1007/s10549-011-1457-7.

Jézéquel P, Frénel JS, Campion L, Guérin-Charbonnel C, Gouraud W, Ricolleau G, Campone M. 2013. Bc-GenExMiner 3.0: new mining module computes breast cancer gene expression correlation analyses. Database, bas060-bas060. DOI: 10.1093/database/bas060.

Hsu C L, Lee W C. 2010. Detecting differentially expressed genes in heterogeneous diseases using half Student's t-test. International Journal of Epidemiology, 39(6):1597-1604. DOI: 10.1093/ije/dyq093.

Cejalvo JM Martínez de Dueñas E, Galván P, García-Recio S, Burgués Gasión O, Paré L, Antolín S, Martinello R, Blancas I, Adamo B, Guerrero-Zotano Á, Muñoz M, Nucíforo P, Vidal M, Pérez RM, Chacón López-Muniz J, Caballero R, Peg V, Carrasco E, Rojo F, Perou CM, Cortés J, Adamo V, Albanell J, Gomis RR, Lluch A, Prat A. 2017. Intrinsic Subtypes and Gene Expression Profiles in Primary and Metastatic Breast Cancer. Cancer Research, 77(9):2213-2221. DOI: 10.1158/0008-5472.CAN-16-2717.

Bansal C, Singh US, Misra S, Sharma KL, Tiwari V, Srivastava AN. 2012. Comparative evaluation of the modified Scarff-Bloom-Richardson grading system on breast carcinoma aspirates and histopathology. CytoJournal, 9(1):4. DOI: 10.4103/1742-6413.92550.

Amat S, Penault-Llorca F, Cure H, Le Bouedëc G, Achard JL, Van Praagh I, Feillel V, Mouret-Reynier MA, Dauplat J, Chollet P. 2002. Scarff-Bloom-Richardson (SBR) grading: a pleiotropic marker of chemosensitivity in invasive ductal breast carcinomas treated by neoadjuvant chemotherapy. International Journal of Oncology, 20(4):791-796. DOI: 10.3892/ijo.20.4.791.

Thiel G, Cibelli G. 2002. Regulation of life and death by the zinc finger transcription factor Egr-1. Journal of Cellular Physiology, 193(3):287-292. DOI: 10.1002/jcp.10178.

Oliveira Fernandes M, Tourtellotte W G. 2015. Egr3-Dependent Muscle Spindle Stretch Receptor Intrafusal Muscle Fiber Differentiation and Fusimotor Innervation Homeostasis. Journal of Neuroscience, 35(14):5566557. DOI: 10.1523/JNEUROSCI.0241-15.2015.

Santino P, Martignani E, Miretti S, Baratta M, Accornero P. 2017. Mechanisms of modulation of the Egr gene family in mammary epithelial cells of different species. General and Comparative Endocrinology, 247:8796. DOI: 10.1016/j.ygcen.2017.01.020.

Silverman E S, Collins T. 1999. Pathways of Egr-1-mediated gene transcription in vascular biology. American Journal of Pathology, 154(3):665-670. DOI: 10.1016/S0002-9440(10)65312-6.

Delmastro M M, Piganelli J D. 2011. Oxidative stress and redox modulation potential in type 1 diabetes. Clinical \& Developmental Immunology, 2011(1):593863. DOI: 10.1155/2011/593863.

Russell DL, Doyle KM, Gonzales-Robayna I, Pipaon C, Richards JS. 2003. Egr-1 Induction in Rat Granulosa Cells by Follicle-Stimulating Hormone and Luteinizing Hormone: Combinatorial Regulation By Transcription Factors Cyclic Adenosine 3',5'-Monophosphate Regulatory Element Binding Protein, Serum Response Factor, Sp1, and Early Growth Response Factor-1. Molecular Endocrinology, 17(4):520-533. DOI: 10.1210/me.2002- 
396

397

398

399

400

401

402

403

404

405

406

407

408

409

410

411

412

413

414

415

416

417

418

419

420

421

422

423

424

425

426

427

428

429

430

431

432

0066.

LeBlanc, S. E. 2005. Direct Regulation of Myelin Protein Zero Expression by the Egr2 Transactivator. Journal of Biological Chemistry, 281(9):5453-5460. DOI: 10.1074/jbc.M512159200.

Nonchev S, et al. 1996. The Conserved Role of Krox-20 in Directing Hox Gene Expression during Vertebrate Hindbrain Segmentation. Proceedings of the National Academy of Sciences of the United States of America, 93(18):9339-9345. DOI: $10.2307 / 39711$.

Li S, Miao T, Sebastian M, Bhullar P, Ghaffari E, Liu M, Symonds AL, Wang P. 2013. The Transcription Factors Egr2 and Egr3 Are Essential for the Control of Inflammation and Antigen-Induced Proliferation of B and T Cells. Immunity, 37(2):685-96. DOI: 10.4161/jkst.23952.

Lu L, Ye X, Yao Q1, Lu A, Zhao Z, Ding Y, Meng C, Yu W, Du Y, Cheng J. 2017. Egr2 enhances insulin resistance via JAK2/STAT3/SOCS-1 pathway in HepG2 cells treated with palmitate. General and Comparative Endocrinology, 2017:S0016648017300722. DOI: 10.1016/j.ygcen.2017.08.023.

Miao T, Symonds ALJ, Singh R, Symonds JD, Ogbe A, Omodho B, Zhu B, Li S, Wang P. 2017. Egr2 and 3 control adaptive immune responses by temporally uncoupling expansion from $\mathrm{T}$ cell differentiation. Journal of Experimental Medicine, 214(6):1787-1808. DOI: 10.1084/jem.20160553.

Wang ZD, Qu FY, Chen YY, Ran ZS, Liu HY, Zhang HD. 2017. Involvement of microRNA-718, a new regulator of EGR3, in regulation of malignant phenotype of HCC cells. Journal of Zhejiang UniversitySCIENCE B, 2017, 18(1):27-36. DOI: 10.1631/jzus.B1600205.

Rebecca P, et al. 2013. Early Growth Response 3 (Egr3) Is Highly Over-Expressed in Non-Relapsing Prostate Cancer but Not in Relapsing Prostate Cancer. PLoS ONE, 8(1):e54096. DOI: 10.1371/journal.pone.0054096.

Baron VT, Pio R, Jia Z, Mercola D. 2014. Early Growth Response 3 regulates genes of inflammation and directly activates IL6 and IL8 expression in prostate cancer. British Journal of Cancer, 112(4):755-764. DOI: 10.1038/bjc.2014.622.

Sorlie T, et al.2001. Gene expression patterns of breast carcinomas distinguish tumor subclasses with clinical implications. Proceedings of the National Academy of Sciences of the United States of America, 98(19):1086974. DOI: 10.1073 /pnas.191367098.

Sorlie T, Tibshirani R, Parker J, Hastie T, Marron JS, Nobel A, Deng S, Johnsen H, Pesich R, Geisler S, Demeter J, Perou CM, Lønning PE, Brown PO, Børresen-Dale AL, Botstein D. 2003. Repeated observation of breast tumor subtypes in independent gene expression data sets. Proceedings of the National Academy of Sciences of the United States of America, 100(14):8418-23. DOI: 10.1073/pnas.0932692100.

Curtis C, et al. 2012. The genomic and transcriptomic architecture of 2,000 breast tumours reveals novel subgroups. Nature ,486:1645. DOI: 10.1038/nature10983.

Saslow D, Boetes C, Burke W, Harms S, Leach MO, Lehman CD, Morris E, Pisano E, Schnall M, Sener S, Smith RA, Warner E, Yaffe M, Andrews KS, Russell CA; American Cancer Society Breast Cancer Advisory Group. 2007. American Cancer Society Guidelines for Breast Screening with MRI as an Adjunct to Mammography. CA, 57(2):75-89. DOI: 10.3322/canjclin.57.2.75.

Peer) reviewing PDF | (2019:07:39303:1:2:NEW 22 Oct 2019) 


\section{Figure 1}

The family of EGR mRNA expression levels in different cancer types.

Figure1. The family of EGR mRNA expression levels in different cancer types. Up: red, down: blue. $\mathrm{P}<0.05$, which confirms statistical significance.Color depth indicates the percentage of gene arrangement. 


\begin{tabular}{|c|}
\hline Analysis Type by Cancer \\
\hline Bladder Cancer \\
\hline Brain and CNS Cancer \\
\hline Breast Cancer \\
\hline Cervical Cancer \\
\hline Colorectal Cancer \\
\hline Esophageal Cancer \\
\hline Gastric Cancer \\
\hline Head and Neck Cancer \\
\hline Kidney Cancer \\
\hline Leukemia \\
\hline Liver Cancer \\
\hline Lung Cancer \\
\hline Lymphoma \\
\hline Melanoma \\
\hline Myeloma \\
\hline Other Cancer \\
\hline Ovarian Cancer \\
\hline Pancreatic Cancer \\
\hline Prostate Cancer \\
\hline Sarcoma \\
\hline Significant Unique Analyses \\
\hline Total Unique Analyses \\
\hline
\end{tabular}

\begin{tabular}{|c|c|c|c|c|c|c|c|}
\hline \multicolumn{2}{|c|}{$\begin{array}{c}\text { Cancer } \\
\text { vs. } \\
\text { Normal } \\
\text { EGR } 1\end{array}$} & \multicolumn{2}{|c|}{$\begin{array}{l}\text { Cancer } \\
\text { vs. } \\
\text { Normal }\end{array}$} & \multicolumn{2}{|c|}{$\begin{array}{l}\text { Cancer } \\
\text { vs. } \\
\text { Normal }\end{array}$} & & \\
\hline & 3 & & 3 & & 1 & & \\
\hline \multirow[t]{3}{*}{1} & & 5 & & 1 & 4 & & 2 \\
\hline & 17 & 1 & 14 & & 4 & & \\
\hline & 1 & & & & 1 & & \\
\hline \multirow[t]{2}{*}{1} & 1 & & & 2 & 1 & & \\
\hline & & 1 & & & & 1 & \\
\hline \multirow[t]{8}{*}{1} & & 1 & 2 & 1 & & & \\
\hline & 2 & & & & & & \\
\hline & 4 & & & & 1 & & \\
\hline & 5 & & 2 & & & & \\
\hline & 4 & & 3 & & 1 & 1 & \\
\hline & & 1 & & & 3 & & \\
\hline & 2 & & & & & & \\
\hline & & & & & 1 & & 1 \\
\hline \multirow[t]{5}{*}{1} & 2 & 1 & & 1 & & & 5 \\
\hline & 2 & & 1 & & 2 & & \\
\hline & & 1 & & & & & \\
\hline & & & 1 & 1 & & & \\
\hline & 5 & & & & & & \\
\hline 4 & 48 & 11 & 26 & 6 & 19 & 2 & 8 \\
\hline \multicolumn{2}{|c|}{361} & \multicolumn{2}{|c|}{345} & \multicolumn{2}{|c|}{351} & \multicolumn{2}{|c|}{310} \\
\hline
\end{tabular}

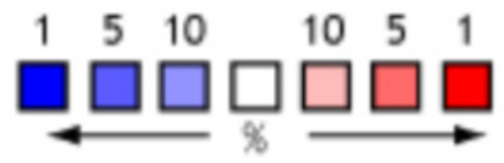


Figure 2

Relationship between EGR family mRNA expression level and prognosis ofBC patients.

Figure 2. Relationship between EGR family mRNA expression level and prognosis of BC patients. OS: overall survival, RFS: completion free survival, DMFS: completion free survival, PPS: post progression survival.
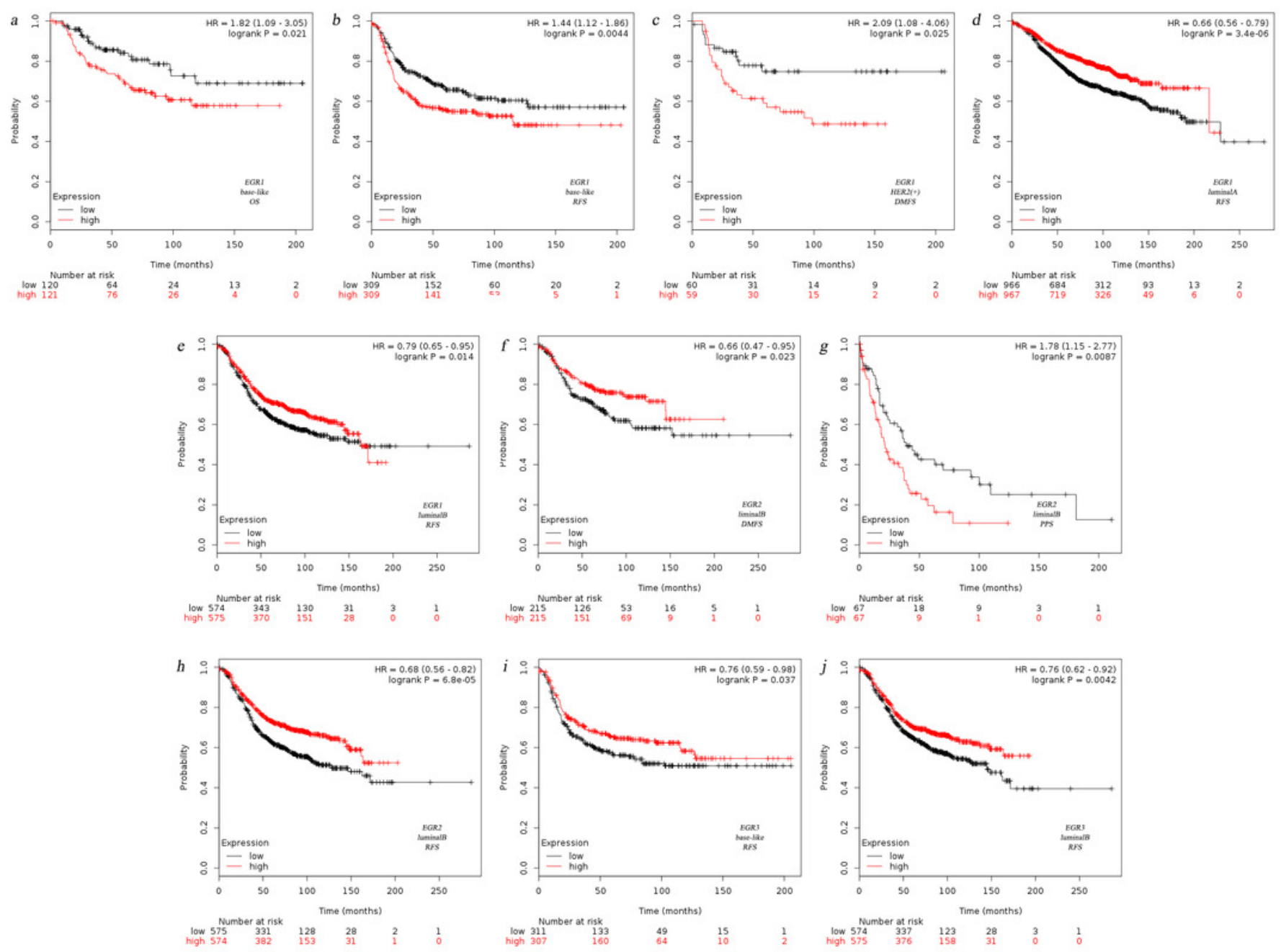

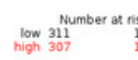

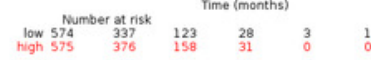


Figure 3

Relationship between EGR family mRNA expression level and SBR gradingstatus.

Figure 3. Relationship between EGR family mRNA expression level and SBR grading status. Welch's test was applied to generate P value. Dunnett's Tukey's Kramer's test was used for pared-to-pared-comparison to evaluate the differences between groups. $\mathrm{P}<0.05$, which confirms statistical significance.
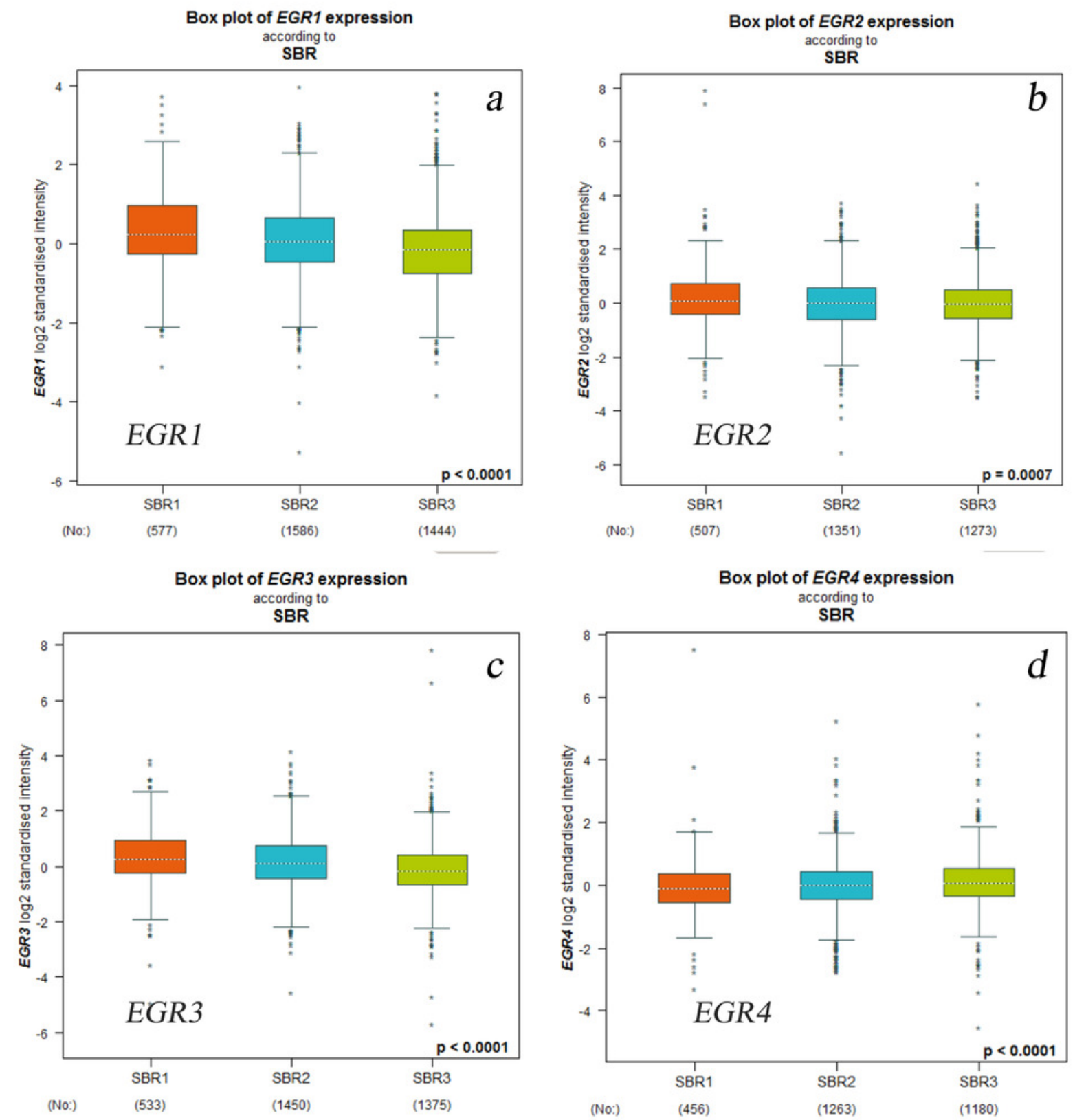
Figure 4

EGR mutations in patients with invasive breast cancer.

Figure 4. EGR mutations in patients with invasive breast cancer. Kaplan-Meier curve depicting a positive association between the mRNA expression level of EGR1/2/3 and MR-free survival (EGR1: $\mathrm{HR} 0.87 ; 95 \% \mathrm{Cl}$ 0.77-0.98, P= 0.0212; EGR2: HR, 0.81; 95\% Cl 0.71-0.92, P=0.0009; EGR3: HR 0.78, 95\% Cl 0.69-0.89, $\mathrm{P}=0.0001)$. EGR4 expression level has no correlation with MR-free survival (HR 1.09; 95\% Cl 0.96-1.24, $\mathrm{P}=0.1660$ ). $\mathrm{EGR}$, Early growth response proteins; $\mathrm{HR}$, hazard ratio; $\mathrm{Cl}$, confidence interval; $\mathrm{MR}$, metastatic relapse.
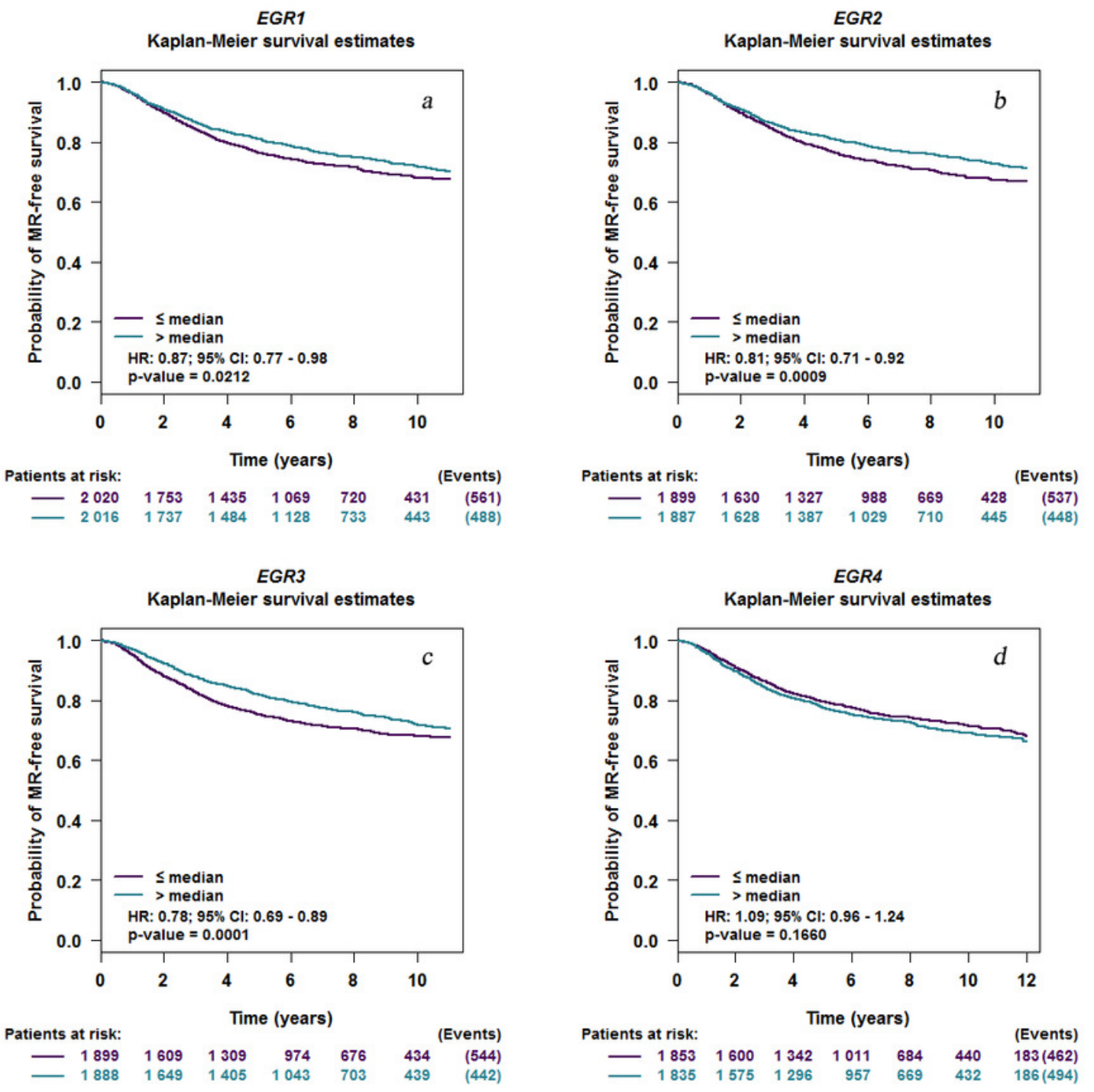


\section{Figure 5}

\section{EGR mutations in patients with invasive breast cancer.}

Figure 5. EGR mutations in patients with invasive breast cancer. (a) Various genetic variations in the EGR family sample. Databeses: Breast Cancer (METABRIC, Nature 2012 \& Nat Commun 2016), Breast Invasive Carcinoma (TCGA, Provisional). (b) Overall survival rates with and without EGR3 copy-number alternations. Logrank Test P-Value: 0.833.(c) The relationship between the number of copies of EGR3 and its mRNA expression level.
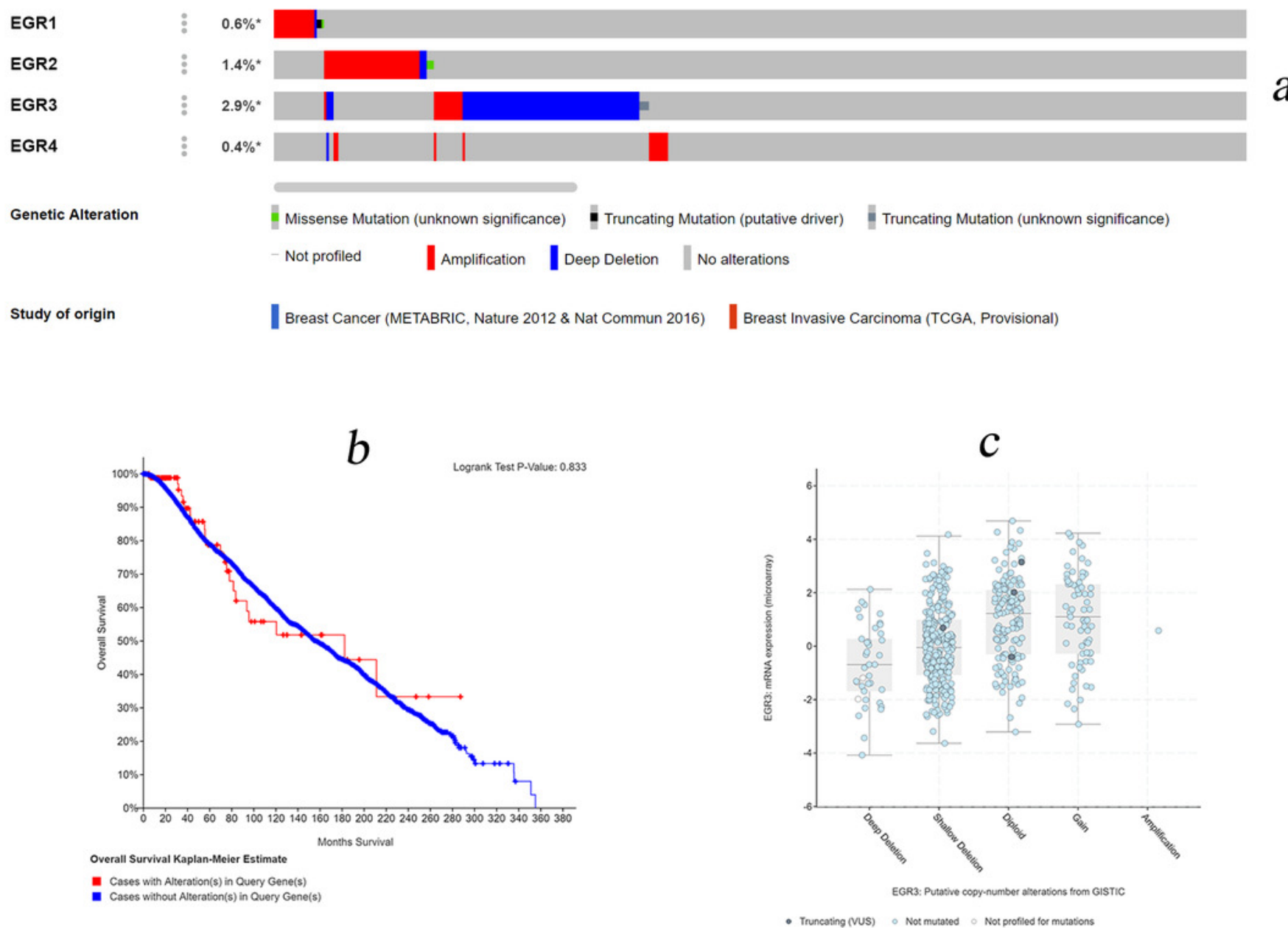


\section{Table $\mathbf{1}$ (on next page)}

Datasets of EGR family in breast cancer.

Solie breast: Sorlie T, et al. 2001, Sorlie T, et al. 2003. ; Ma breast : Saslow D, et al. 2007. ; Curtis breast : Curtis et al, 2012. 
Table1. Datasets of EGR family in breast cancer.

\begin{tabular}{|c|c|c|c|c|c|}
\hline Gene & Dataset & Type of BC vs. breast & Fold change & P-value & t-Test \\
\hline \multirow[t]{15}{*}{ EGR1 } & TCGA breast & Invasive $\mathrm{BC}$ & -6.692 & $1.35 \mathrm{E}-25$ & -12.908 \\
\hline & & Invasive Ductal BC & -14.944 & $3.23 \mathrm{E}-41$ & -23.74 \\
\hline & & Invasive Loublar BC & -7.001 & $5.60 \mathrm{E}-13$ & -9.119 \\
\hline & Solie breast & Ductal BC & -13.473 & $3.68 \mathrm{E}-20$ & -20.081 \\
\hline & Solie breast 2 & Loublar BC & -11.284 & 4.14E-05 & -10.364 \\
\hline & & Ductal BC & -13.369 & 2.57E-09 & -20.244 \\
\hline & Ma breast 4 & Ductal BC in situ epithelia & -7.073 & $6.62 \mathrm{E}-05$ & -4.738 \\
\hline & Richardson breast 2 & Ductal BC & -11.306 & $2.29 \mathrm{E}-12$ & -12.684 \\
\hline & Perou breast & Ductal BC & -14.193 & $1.37 \mathrm{E}-16$ & -20.785 \\
\hline & Curtis breast & Invasive Ductal BC & -6.866 & $2.02 \mathrm{E}-127$ & -47.813 \\
\hline & & Invasive Loublar BC & -4.156 & $2.54 \mathrm{E}-47$ & -18.611 \\
\hline & & Invasive $\mathrm{BC}$ & -5.165 & $8.43 \mathrm{E}-08$ & -7.631 \\
\hline & & Medullary BC & -9.539 & $6.13 \mathrm{E}-18$ & -15.918 \\
\hline & & Tubular BC & -4.04 & $1.45 \mathrm{E}-26$ & -15.102 \\
\hline & & Mucinous BC & -5.765 & $2.07 \mathrm{E}-18$ & -13.128 \\
\hline \multirow[t]{12}{*}{ EGR2 } & TCGA breast & Invasive $\mathrm{BC}$ & -3.172 & $3.34 \mathrm{E}-13$ & -8.043 \\
\hline & & Invasive Ductal BC & -5.759 & $3.17 \mathrm{E}-24$ & -14.683 \\
\hline & & Invasive Loublar BC & -3.723 & 1.43E-09 & -6.811 \\
\hline & Curtis breast & Invasive Ductal BC & -5.022 & $9.45 \mathrm{E}-63$ & -26.986 \\
\hline & & Invasive Loublar BC & -3.803 & $2.41 \mathrm{E}-42$ & -16.084 \\
\hline & & Invasive $\mathrm{BC}$ & -4.413 & $5.08 \mathrm{E}-08$ & -7.497 \\
\hline & & Tubular BC & -3.917 & $1.40 \mathrm{E}-28$ & -14.009 \\
\hline & & Medullary BC & -4.301 & $6.68 \mathrm{E}-21$ & -13.905 \\
\hline & & Mucinous BC & -4.388 & 4.67E-15 & -10.103 \\
\hline & Ma breast 4 & Ductal BC in situ stroma & -3.037 & $4.06 \mathrm{E}-07$ & -6.737 \\
\hline & & Ductal BC in situ epithelia & -15.213 & $1.32 \mathrm{E}-06$ & -6.845 \\
\hline & Richardson breast 2 & Ductal BC & -8.765 & $6.36 \mathrm{E}-09$ & -12.409 \\
\hline \multirow[t]{3}{*}{ EGR3 } & TCGA breast & Invasive $\mathrm{BC}$ & -4.301 & $1.26 \mathrm{E}-14$ & -8.544 \\
\hline & & Invasive Ductal BC & -8.619 & $8.09 \mathrm{E}-29$ & -16.565 \\
\hline & Curtis breast & Medullary BC & -2.249 & $3.92 \mathrm{E}-33$ & -15.057 \\
\hline$\square$ & Richardson breast 2 & Ductal BC & -10.627 & $2.93 \mathrm{E}-06$ & -7.733 \\
\hline
\end{tabular}




\section{Table 2 (on next page)}

Comparison of EGR expression betweenpatients with breast cancer and different clinicopathological parameters.

The number of patients included was determined by the EGR data set. $\uparrow$, up expression; $\downarrow$, lower expression. 
Table2.Comparison of EGR expression between patients with breast cancer and different clinicopathological parameters.

\begin{tabular}{|c|c|c|c|c|c|c|c|c|c|c|c|c|}
\hline \multirow[b]{3}{*}{ Variable } & \multicolumn{3}{|c|}{ EGR1 mRNA } & \multicolumn{3}{|c|}{ EGR2 mRNA } & \multicolumn{3}{|c|}{ EGR3 mRNA } & \multicolumn{3}{|c|}{ EGR4 mRNA } \\
\hline & \multirow{2}{*}{$\begin{array}{l}\text { Numbers of } \\
\text { patients }\end{array}$} & \multirow{2}{*}{$\begin{array}{l}\square \\
\text { Expression } \\
\end{array}$} & \multirow{2}{*}{$\square$} & \multicolumn{2}{|c|}{ Numbers of } & \multirow{2}{*}{$\begin{array}{l}\square \\
\text { P- } \\
\text { value }\end{array}$} & \multicolumn{2}{|c|}{ Numbers of } & \multirow{2}{*}{$\begin{array}{l}\square \\
\text { P-value }\end{array}$} & \multicolumn{2}{|c|}{ Numbers of } & \multirow{2}{*}{$\begin{array}{l} \\
\text { P-value }\end{array}$} \\
\hline & & & & patients & Expression & & patients & Expression & & patients & Expression & \\
\hline \multicolumn{13}{|l|}{ ER,IHC } \\
\hline+ & 4034 & $\uparrow$ & $<.0001$ & 3632 & $\downarrow$ & 0.0104 & 3855 & $\uparrow$ & $<0.0001$ & 3391 & $\downarrow$ & $<0.0001$ \\
\hline- & 1586 & - & & 1416 & - & & 1529 & - & & 1290 & - & \\
\hline \multicolumn{13}{|l|}{ PR,IHC } \\
\hline+ & 1413 & $\uparrow$ & $<0.0001$ & 1117 & - & 0.9781 & 1307 & $\uparrow$ & $<0.0001$ & 1039 & $\downarrow$ & 0.0009 \\
\hline- & 1048 & - & & 776 & - & & 918 & - & & 718 & - & \\
\hline \multicolumn{13}{|l|}{ HER2,IHC } \\
\hline+ & 200 & $\downarrow$ & 0.0297 & 184 & - & 0.6631 & 184 & - & 0.481 & 175 & - & 0.4931 \\
\hline- & 1592 & - & & 1405 & - & & 1405 & - & & 1365 & - & \\
\hline \multicolumn{13}{|c|}{ Nodal status } \\
\hline+ & 1744 & $\downarrow$ & 0.0338 & 1493 & - & 0.1094 & 1494 & - & 0.1805 & 1330 & $\downarrow$ & 0.0016 \\
\hline- & 2398 & - & & 2399 & - & & 2399 & - & & 2232 & - & \\
\hline \multicolumn{13}{|l|}{ Age } \\
\hline$>51$ & 2212 & - & 0.431 & 2093 & $\downarrow$ & 0.0387 & 2094 & $\downarrow$ & 0.002 & 1829 & $\downarrow$ & 0.0285 \\
\hline$\leq 51$ & 1474 & - & & 1343 & - & & 1343 & - & & 1235 & - & \\
\hline \multicolumn{13}{|c|}{$\begin{array}{l}\text { Triple-negative } \\
\text { status }\end{array}$} \\
\hline TNBC & 416 & $\downarrow$ & $<0.0001$ & 3704 & - & 0.7152 & 373 & $\downarrow$ & $<0.0001$ & 3519 & $\downarrow$ & $<0.0001$ \\
\hline Not $T$ NBC & 4133 & - & $\square$ & 373 & - & $\square$ & 3946 & - & $\square$ & 361 & - & $\square$ \\
\hline
\end{tabular}




\section{Table 3 (on next page)}

Dunnett - Tukey - Kramer's test for pairwise comparison in SBR criterion.

SBR, Scarff -Bloom -Richardson. P value, when $p<0.05$, there is a significant statistical difference. 
Table 3. Dunnett-Tukey-Kramer's test for pairwise comparison in SBR criterion.

\begin{tabular}{|c|c|c|c|}
\hline mRNA & The comparison of SBR & The comparison of mRNA expression & P-value \\
\hline \multirow[t]{3}{*}{ EGR1 } & SBR1 vs. SBR2 & $\mathrm{SBR} 2<\mathrm{SBR} 1$ & $<0.0001$ \\
\hline & SBR2 vs. SBR3 & $\mathrm{SBR} 3<\mathrm{SBR} 2$ & $<0.0001$ \\
\hline & SBR1 vs. SBR3 & SBR3<SBR1 & $<0.0001$ \\
\hline \multirow[t]{3}{*}{ EGR2 } & SBR1 vs. SBR2 & SBR2<SBR1 & $<0.01$ \\
\hline & SBR2 vs. SBR3 & $\mathrm{SBR} 2=\mathrm{SBR} 3$ & $>0.10$ \\
\hline & SBR1 vs. SBR3 & $\mathrm{SBR} 3<\mathrm{SBR} 1$ & $<0.001$ \\
\hline \multirow[t]{3}{*}{ EGR3 } & SBR1 vs. SBR2 & SBR2<SBR1 & $<0.01$ \\
\hline & SBR2 vs. SBR3 & $\mathrm{SBR} 3<\mathrm{SBR} 2$ & $<0.0001$ \\
\hline & SBR1 vs. SBR3 & SBR3<SBR1 & $<0.0001$ \\
\hline \multirow[t]{2}{*}{ EGR4 } & SBR1 vs. SBR2 & $\mathrm{SBR} 1=\mathrm{SBR} 2$ & $>0.10$ \\
\hline & SBR2 vs. SBR3 & $\mathrm{SBR} 2<\mathrm{SBR} 3$ & $<0.01$ \\
\hline$\square$ & SBR1 vs. SBR3 & SBR $1<$ SBR3 & $<0.001$ \\
\hline
\end{tabular}

